\title{
Administrative Boundary Design in Support of SDI Objectives
}

\author{
Serryn Eagleson and Francisco Escobar
}

\subsection{INTRODUCTION}

Health, wealth and population distributions are all examples of spatial data commonly referenced to administrative boundaries. In fact, there are few areas of the economy and environment that do not rely either directly or indirectly on the integration of data attached to administrative boundaries for planning, maintaining or rationalising activities. Conceptually, as outlined in Chapter 2, an SDI incorporates the technology, policies, standards and human resources necessary to facilitate the integration of administrative boundary data. In practice, however, the fragmentation of administrative boundaries is a serious problem that restricts the integration and potential benefits of spatial data. As outlined by Flowerdew and Green (1994), situations frequently arise where the analyst wants to compare a variable that is available for one set of administrative units with a variable that is only obtainable for a different incompatible set.

A number of organizations have realised the advantages of using administrative boundaries for the collection and collation of data. For example, once the administrative boundaries are established, the data is easy collected and efficient to store. Even in light of technological advancements, other forms of spatial data, such as address point and line data are still relatively expensive to produce, difficult to manipulate and require large amounts of memory to store (Rajabifard and Williamson, 2001). Many organizations are thus using established polygon-based administrative boundaries as a base for the collection and collation of spatial data. As we move into an era of spatial decision-making, there is recognition amongst the users that current technical issues relating to the noncoterminous alignment of administrative-boundaries need to be addressed.

Imagine someone has just obtained the census data detailing the population distribution attached to boundary set A. They are interested in planning a new healthcare facility. To determine the best location for this facility, the person needs to cross-analyse the census data with health statistics that are reported on boundary set $B$. Due to the incompatible boundary systems used by the agencies, though, it is not possible to accurately and efficiently cross-analyse the health and demographic data. Consequently, the user must rely on their own judgement, to compare the datasets and decide the most logical position for the new centre.

The objective of this chapter is to highlight future directions of administrative boundary design, delineation and dissemination that meet the needs of stakeholders within the SDI framework. To achieve this objective, the chapter proposes the 
development of an administrative boundary hierarchy to facilitate the design, delineation and dissemination of administrative boundaries in support of SDI objectives.

\subsection{A DEFINITION OF THE SPATIAL-HIERARCHY PROBLEM}

Historically, countries have divided social, economic and political responsibilities amongst a variety of agencies. In turn, these agencies have established independent administrative, planning and political boundaries that rarely coincide (Robinson and Zubrow, 1997; Huxhold, 1991). Figure 15.1, illustrates an abstract view of the current situation. Each agency establishes a differently sized or shaped spatial unit, based on their individual - and often unique - requirements, using the land parcel (in most cases) as the bottom layer. In turn, each agency aggregates these boundaries in a hierarchical fashion to cover the state. Data integration is possible within each agency; however, under this current system additional methods such as data interpolation must be employed to facilitate cross-analysis between agencies.

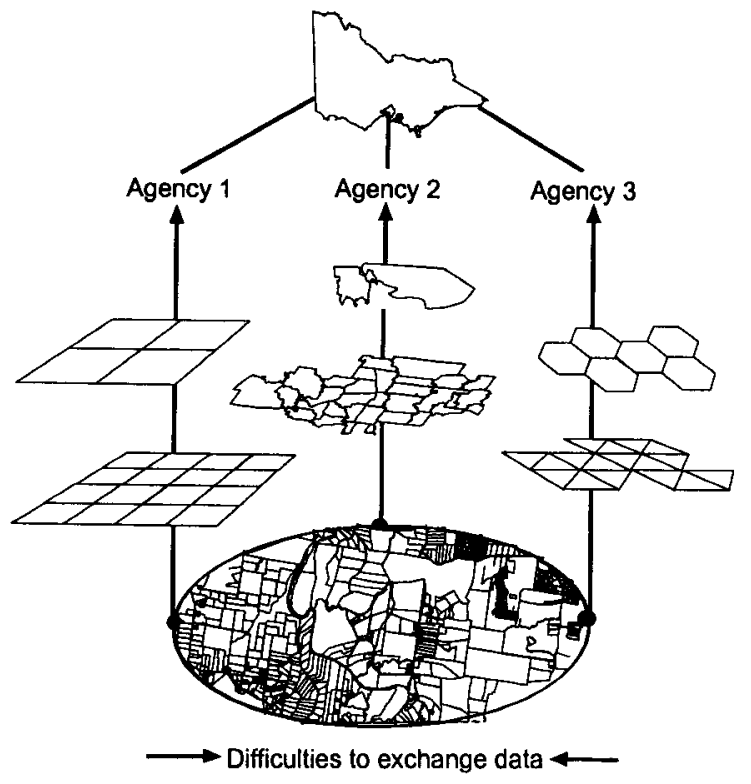

Figure 15.1 An abstract Illustration of the Various Boundary Layers that Exist in Victoria (Adapted from Eagleson et al., 2002a)

Essentially, the spatial-hierarchy problem has occurred because, in the beginning, individual organizations hand-drafted the majority of boundaries on paper maps. With advances in technology, these hand-drafted maps have been digitised for incorporation into GIS, a technology for which they have not been adequately designed. In an effort to improve data integration between noncoterminous administrative boundary layers, a number of methods have been developed to enhance data integration. As detailed below, surface modelling, data 
interpolation, derived boundaries and data re-aggregation are techniques developed to facilitate data integration between non-coterminous boundary units.

\subsubsection{The First Solution: Surface Modelling}

Within a GIS, administrative boundaries are traditionally defined by $(x, y)$ coordinates, and these coordinates are joined by lines, forming closed polygons. To overcome the problem of data integration between two non-coterminous polygon layers, Martin and Bracken (1991), and Bracken, (1994) have developed rasterbased models to integrate the originally polygon-based data. Using their model, variables attached to administrative boundary polygons, such as census districts or postcodes, are referenced to the polygon centroid and converted to point data. Various techniques are then used to map this data onto a raster-based density surface, thus allowing the data to be easily represented and integrated with other raster-based datasets.

Although the raster-based model does facilitate data integration and exchange, limitations do exist. For example, the transfer of data between data structures inevitably causes errors in the accuracy of the data. Additionally, as highlighted by Morphet (1993), boundaries themselves can often add valuable information in analysis; therefore, it is not always sensible to exclude them from the data analysis.

\subsubsection{The Second Solution: Data Interpolation}

The problem of cross-analysing data between two boundary systems can be restated as the problem of deriving data for one set of boundaries given the relevant data for another set. Techniques that are able to complete this process of data transfer between boundary units are commonly known as areal interpolation techniques (Flowerdew and Green, 1994). Areal interpolation often requires complicated mathematical algorithms for the transfer of attribute data between non-coterminous boundary systems (Goodchild et al., 1993; Martin 1998; Trinidad and Crawford, 1996). Although the interpolation process appears to provide an approximate solution to the problem, many assumptions are made in the process. One, often invalid, assumption is that the distributions of values in the original source map are constant (Goodchild et al., 1993).

In an effort to increase the accuracy of interpolation, and minimise the number of assumptions, supplementary data such as road networks, land-use maps, satellite imagery, road networks and administrative boundaries are often used as "controls" for the interpolation process. Although areal interpolation techniques are valuable for providing a basis for analysis not currently possible with a single boundary layer, the errors and assumptions inherent in the techniques can lead to a less than optimum solution (Eagleson et al., 2002b). 


\subsubsection{The Third Solution: Derived Boundaries}

In an attempt to make data readily usable, some organizations have created derived boundaries. Derived boundaries are formed through the re-aggregation of agency boundaries that approximately nest within more publicly recognizable administrative units. One example is the derived postcodes generated in Australia by the Australian Bureau of Statistics (ABS). For operational reasons, the Australia Post postcode boundaries do not necessarily match the ABS census collector district (CCD) boundaries. In recognition of the separate functions undertaken by these agencies, the ABS aggregates CCDs to approximate the Australia Post postcode boundaries, producing ABS derived postal areas. Discrepancies between the boundaries of these two postal zones can easily arise since the two systems are not coordinated. The derived postal areas may be quite different from the actual postcode boundaries, both in terms of shape and area. Figure 15.2, illustrates the problem. The two sets of spatial entities (postal zones) are, nevertheless, given the same identifier by the agencies, consequently leading to the misinterpretation of data by users. A discussion on this issue can be found in Jones et al. (2003). If users remain uninformed about the origin of the data boundaries, subsequent decisions will not be well supported. The use of these derived boundaries can lead to confusion between agencies using the data when differences between derived postcodes and postcodes cannot be clearly identified by the user.

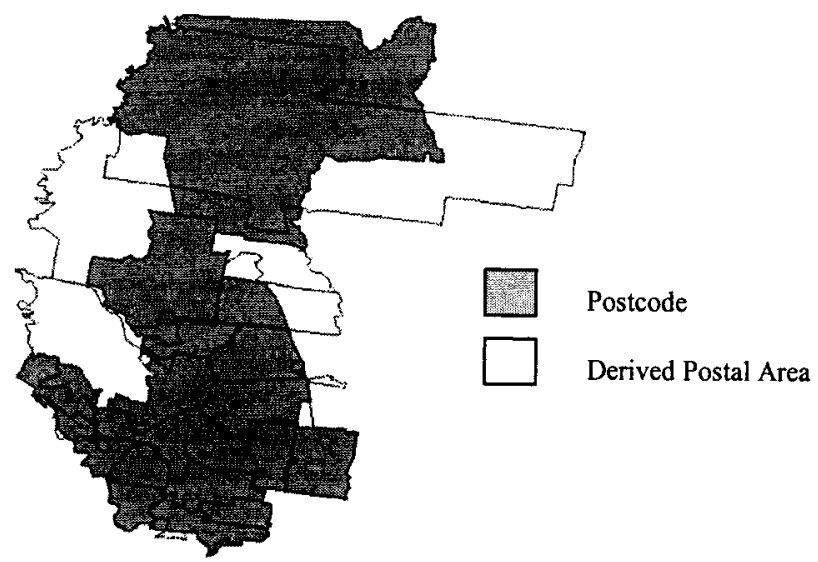

Figure 15.2: An Illustration of the Difference Between Derived Postcode Boundaries and Actual Postcode Boundaries in the North West Melboume Health Division

\subsubsection{The Fourth Solution: Re-Aggregation}

A fourth method for the dissemination of datasets across incompatible boundary regions is the re-aggregation of point data and polygon data. The re-aggregation of point data requires data to be stored at a parcel level and aggregated to a different 
spatial unit at any time. Although the process of aggregation accurately solves the problem, other problems exist.

First, this solution is not viable in Australia and many other countries, primarily due to stringent laws protecting confidentiality. For instance, once household data is collected by the ABS, it must be aggregated to the CCD boundaries (approximately 220 households) and the individual household data destroyed (ABS, 1998). If confidentiality is not guaranteed, it is probable that people will not complete census forms truthfully, degrading the accuracy and reliability of census information for planning purposes.

Second, a large quantity of storage space is required to store data associated with individual land parcels, and each re-aggregation of data to new boundaries would be extremely time consuming and costly. Additionally, problems such as differencing exist when data is aggregated to a number of different boundaries. As Duke-Williams and Rees (1998) explain, if polygons containing confidential information are overlapping, in some circumstances it may be possible to subtract one set of polygons from the other to obtain statistics for subthreshold areas, thus breaching confidentiality.

The re-aggregation of polygon data involves the re-aggregation of existing units into new boundaries more suitable for specific analysis techniques. For example, Openshaw (1977) devised the automated-zone-design program (AZP) for investigating the modifiable-area-unit problem (MAUP). With the introduction of new technology, digital data and improved algorithms during the 1990s, AZP was further refined and extended forming the zone-design system (ZDES) (Openshaw and Rao, 1995; Openshaw and Alvanides, 1999). These zone-design systems allow the analyst the freedom to start with data at one scale and then re-aggregate it to create a new set of regions designed to be suitable for a specific purpose, independent of the collection boundaries used (Openshaw and Rao, 1995). If these initial boundaries are not designed as layers within a hierarchy, however, the problem of data integration between overlapping polygons remains. Although research has been conducted into the cross-analysis of boundary-referenced data, the problem of incompatible boundary design is still a major concern for spatial analysts around the world. These concerns are largely due to the limited accuracy and specialist skills that may be required to operate the technical solutions. The issue of technical skills is one of the problems limiting the diffusion of GIS in a number of applications such as social-service planning as highlighted by Hugo (1997):

In GIS, as in all technology, there is a real danger that the elite will gain control of it and that access among the mass community will remain limited. This must be guarded against especially since the technology and methodology of GIS, as in other areas involving computers, is becoming cheaper and more user-friendly and not necessitating years of training to interface with and use.

The core components of SDI - in relation to administrative boundaries - requires further development to address the issues of data integration between noncoterminous administrative boundaries and to empower the SDI framework to facilitate an optimum level of analysis in the spatial-information industry. 


\subsection{ADMINISTRATIVE BOUNDARIES WITHIN SDI}

The spatial industry has experienced a transition phase from being data-poor, especially in terms of spatial data, to one that is now comparatively data rich. However, the means of organising, managing and using data to which there is now access have not kept pace with the need to make informed decisions and the technology now available (Openshaw 1998; UCGIS 2000). In order to meet the future needs of spatial-information analysts, institutional initiatives must be developed to address the different aspects of administrative boundary integration, sharing and management within an SDI (Feeney et al., 2002).

It is proposed that well structured SDIs can reduce data duplication and facilitate data integration across administrative boundary systems and through time. The following section of this chapter addresses each of the five SDI components discussed in Chapter 2 and highlights their role in coordinating administrative boundary data integration.

\subsubsection{Access}

Improved technology and the greater penetration of GIS into government, business and society has produced a driving need for access to reliable and accurate spatial data (Nairn and Holland, 2001). Due to economics, culture and laws governing the extent of disclosure of spatial information, however, it is often impossible for spatial-information analysts to gain access to the data they require.

Administrative boundaries fulfil a niche within the spatial data market. They are relatively inexpensive to produce, meet privacy standards and provide spatial analysts with a plethora of information. Postcodes are a prime example of administrative boundaries within the SDI "... with postcodes you can locate people and see the hows, where's and whys of markets, customers and prospects, competitors, prices, suppliers, routes and profits. Postcodes neatly define convenient demographic zones and are familiar to everyone" (Geoscience Australia, 2001). As the potential of data analysis based on administrative boundaries is realised, policy related to data-access issues - such as pricing, copyright and licensing along with technical data standards - needs to be firmly established.

\subsubsection{People}

The interaction between the users of spatial data, data suppliers and any valueadding agents in between them drives the development of any SDI (Chan et al., 2001; Rajabifard et al., 2000). Considering the important and dynamic interaction between people and data, to develop effective SDIs, it is important to consider the changing nature of communities and their needs, which, in return, requires different standards and sets of administrative boundary data

In general, users of administrative boundary data are far more experienced and aware than previously and have increasingly demanding and more diverse expectations (Openshaw et al., 1998). As a result, there is an increasing need to 
deliver administrative boundaries that meet the needs of users. One problem creating confusion amongst spatial-information analysts is the attempt by some organizations to aggregate their data to boundaries that are representatives of existing publicly recognizable units, such as the derived boundaries discussed in section 15.3 .

\subsubsection{Data}

Boundaries are no longer just mechanisms through which order can be created and maintained. They can also act as a spatial device through which improved economic, social and environmental decision-making can take place (Marquart and Crumley, 1987). In order for this process to occur effectively, however, aside from the general data requirements relating to the content, quality, condition and completeness of spatial dataset, the issues of confidentiality and the modifiablearea-unit problem (MAUP) present two problems specific to the development of data attached to administrative boundary polygons.

\section{(a) Confidentiality}

The use of personal information within GIS arouses the conflict between societies' demand for increasingly accurate information and individuals' rights to preserve their privacy (Escobar et al., 2001). The vast majority of social databases have grown from information collected from individuals and groups. The importance of maintaining confidentiality in the use of these databases is imperative to both the individuals and the public standing of the agencies involved in the data collection. As many social applications rely heavily on client-group confidence and the cooperation of community groups operating in the field, the development of improved inter-agency data exchange must be accompanied by effective procedures that protect individual confidentiality (ABS, 1998).

\section{(b) The Modifiable-Area-Unit Problem (MAUP)}

The MAUP is a form of ecological fallacy associated with the aggregation of individual data into areal units for spatial analysis (Fotheringham and Wong, 1991). An example of the process is census data, which is collected from every household but released only at census boundaries. When the values are averaged through the process of aggregation, variability in the dataset is lost, and values of statistics computed at different boundary resolutions will be different. This is called the scale effect. In addition to the scale effect, the analyst gets different results depending on how the spatial aggregation occurs. The MAUP is integral to the display of demographic data as the information relayed through mapping and statistics is a product of the size, shape and scale of the administrative boundaries used in the data-aggregation process. As outlined by Openshaw et al. (1998), in the past, the MAUP has been largely ignored by administrative agencies, with analysts unable to alter the boundaries provided to them. As a result, new developments are required to enable spatial analysts the freedom to design new output areas for the 
analysis of spatial data at a range of scales and aggregations, whilst preserving confidentiality.

\subsubsection{Technical Standards}

Technical standards are essential for efficient sharing of products and to provide information about spatial data. Technical standards are designed to simplify access and data quality and integration. Currently, the SDI policies, in general, have been designed to govern reference systems, data models, data dictionaries, data quality, data transfer and metadata. One area that needs to be fully developed is that of technical standards relating to the design, update, maintenance, consistency and cartographic representation of administrative boundaries. The Kansas Geospatial Jurisdictional and Administrative Boundaries Standard is an example of a set of standards that have been developed to facilitate the maintenance, representation and dissemination of boundary information so that it can be more easily integrated with other spatial structures (DASC, 1999).

The role of the standards is to provide 'best practise guidelines' to ensure that all maps, boundary descriptions, district names, and digital representations are complete, current and correct. As digital administrative boundary maps become commonplace, they will be used more frequently by a wide number of people. It is expected that these people will be using the data on a daily basis and will require more frequent updates of the data (DASC, 1999).

One technical issue related to standards that is highlighted in this chapter is the design criteria for new political and administrative boundaries. One initiative, that has been undertaken within Victoria, Australia by the authors is the reorganization of administrative boundaries into a coordinated hierarchy based on hierarchical-spatial-reasoning (HSR) theory.

\section{(a) Hierarchical Spatial Reasoning (HSR) Applied to Administrative Boundaries}

It is proposed that the reorganization of administrative-agency boundaries within a common, hierarchical spatial framework will enhance data integration and analysis methods. Figure 15.3 illustrates the proposed solution. Through the application of HSR theory, the spatial boundaries of different agencies are organised in a coordinated hierarchical system (Car, 1997). Data exchange and aggregation is possible within, and amongst, individual agencies, providing aggregated data at all levels. Currently, hierarchical properties are used in an array of different disciplines to break complex problems into subproblems that can be solved in an effective manner (Timpf and Frank, 1997). Although spatial hierarchies are designed using the same principles - to break complex tasks into subtasks or areas relationships between levels within the hierarchies are complex (refer to Chapter 2). Section 15.4.4.2 details the structural complexities involved in the creation of a coordinated spatial-hierarchy model. 


\section{(b) The Structure of Administrative Boundaries}

Structurally, within a GIS, administrative boundaries are considered as objects in a layer, such that each layer contains the same type of boundaries interacting in the same way among themselves (Car, 1997). The layers differ only in the degree of detail; therefore, to establish each layer in a hierarchy a set of rules are required. These rules must consider the boundary layer from both a functional and analytical perspective. Arguably, one of the most complex problems to overcome is the lack of clear business rules and constraints governing the design and shape of administrative boundaries. To be successful, it is imperative that common criteria can be established for the design of coordinated administrative boundaries. Figure 15.3 illustrates an example of a spatial hierarchy. The cadastre forms the base layer because the smallest administrative unit stored in the system determines the most detailed boundary system available (Volta and Egenhofer, 1993), and the cadastre is one of the most important infrastructure layers available (Dale and McLaughlin, 1988).

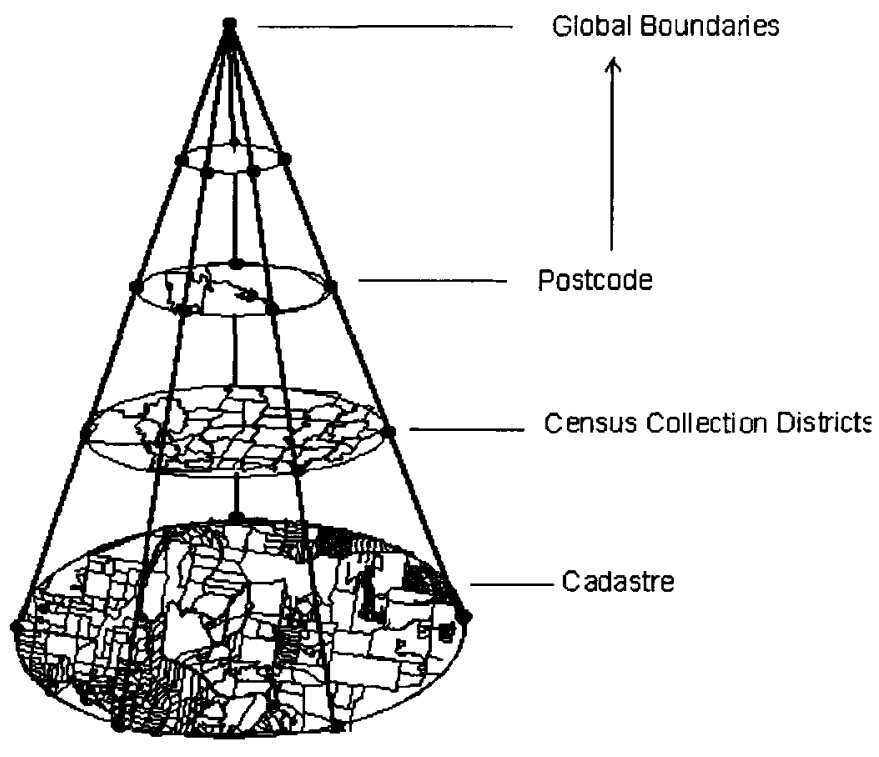

Figure 15.3: Future hierarchically organised administrative structures (Adapted from Eagleson et al., 2002b)

The development of a coordinated spatial-hierarchy is intended to provide a framework in which agencies are able to construct administrative boundaries based on a common spatial layer, in this instance the cadastre. These boundaries are then aggregated to form new administrative units that meet the needs of more than one agency. If required, it is also possible for spatial-information analysts to create synthetic boundaries based on the core boundaries within the hierarchy. These synthetic boundaries allow the analyst freedom to examine alternative scenarios, whist preserving the confidentiality of individuals. 


\subsubsection{Policy}

It has been established that exchanging, sharing and integrating spatial data based on administrative boundaries from various sources has become increasingly important. As described above, however, little policy governing the design and delineation of administrative boundaries exists, with emphasis predominately, focussed on technical aspects of boundary design (Eagleson et al., 2002a; 2002b). Nevertheless, it has been proven that it is technically possible to develop a hierarchy of boundary units based on the criteria of two agencies. It is therefore important to develop policy that will further support these technological advancements. This will, in turn, facilitate the sharing and exchange of information between the public and the private sectors.

It must be recognised, though, that developing a policy alone cannot ensure the free flow of information from one organization to another unless institutional issues are addressed. In order to begin addressing these issues, there is a need to better understand the complex nature of SDIs and their ability to facilitate the implementation of new methods for designing administrative boundaries in the future.

To further promote the coordinated design of administrative boundaries, it is proposed that incentives for agencies to participate in the hierarchical design framework need to be established. These incentives may include the accreditation of agencies establishing boundaries within the spatial-hierarchy and/or benchmarking administrative boundary hierarchies to assess the comparative effectiveness of the system in facilitating data integration and exchange. As detailed below in Section 15.4.6 there are a number of recommendations that could improve SDIs and, consequently, improve the integration and exchange of data attached to administrative boundary systems.

\subsubsection{Summary}

The role of administrative boundaries has changed from that of an era of analogue mapping by individual agencies to the realised need for a coordinated boundary system incorporating the requirements of many SDI stakeholders. Additionally, technology is, to a certain degree, driving the way agencies do business. For example, the Internet has been suggested as a future tool to conduct censuses (Mobbs, 1998). If this form of collection is realised then the boundary delineation criteria set for establishing boundaries to represent this data will no longer need to consider the distance and time taken by census collectors; therefore, the method established for boundary design will need to be flexible and dynamic, taking into account the technology-related changes of the future.

Table 15.1 summarises the components of SDI and the mechanisms required to guide the design, delineation and dissemination of administrative boundaries and polygon-based data into the future. 
Table 15.1: The Role of SDI and Recommendations to Facilitate the Use of Administrative Boundary Data

\begin{tabular}{|c|c|c|}
\hline (3) & Role of an SDI & Recommendations \\
\hline $\begin{array}{l}\text { Access } \\
\text { Networks }\end{array}$ & $\begin{array}{l}\text { Provide users with } \\
\text { mechanisms to access } \\
\text { administrative boundary } \\
\text { data. }\end{array}$ & $\begin{array}{l}\text { - Improve data availability and ongoing } \\
\text { assessment of requirements. } \\
\text { - Provide a range of data products at different } \\
\text { file sizes to facilitate a range of user needs. }\end{array}$ \\
\hline People & $\begin{array}{l}\text { Develop partnerships } \\
\text { between administrative } \\
\text { boundary users and the } \\
\text { agencies establishing } \\
\text { administrative boundaries. }\end{array}$ & $\begin{array}{l}\text { - Educate spatial-data users. } \\
\text { - Promote the benefits of spatial data amongst } \\
\text { potential users. } \\
\text { - Develop mechanisms to assess the } \\
\text { requirements of users. }\end{array}$ \\
\hline $\begin{array}{l}\text { Technical } \\
\text { Standards }\end{array}$ & $\begin{array}{l}\text { Provide standards for the } \\
\text { design, delineation and } \\
\text { dissemination of } \\
\text { administrative boundaries. }\end{array}$ & $\begin{array}{l}\text { Establish criteria for boundary delineation. } \\
\text { - Establish methods for automated boundary } \\
\text { delineation. } \\
\text { - Derive metadata standards specific to } \\
\text { administrative boundaries. } \\
\text { - Provide guidelines for the cartographic } \\
\text { representation of boundaries. } \\
\text { - Improve mechanism for updating } \\
\text { boundaries and providing notification of } \\
\text { changes made. }\end{array}$ \\
\hline Data & $\begin{array}{l}\text { Provide standards for data } \\
\text { attached to administrative } \\
\text { boundaries. } \\
\text { Reduce the cost of data } \\
\text { production and } \\
\text { dissemination. }\end{array}$ & $\begin{array}{l}\text { - Facilitate the development of complete and } \\
\text { up-to-date data beneficial for a range of } \\
\text { applications. } \\
\text { - Reduce duplication of datasets. }\end{array}$ \\
\hline Policy & $\begin{array}{l}\text { Facilitate the design of } \\
\text { policy for the coordinated } \\
\text { design, delineation and } \\
\text { dissemination of } \\
\text { administrative boundaries } \\
\text { and associated metadata. }\end{array}$ & $\begin{array}{l}\text { - Make ongoing assessment of requirements. } \\
\text { - Provide guidelines to data custodians. } \\
\text { - Delineate technology and methods. } \\
\text { - Access and disseminate methods } \\
\text { established. } \\
\text { - Provide incentives to participate; i.e. } \\
\text { accreditation, benchmarking and standards. } \\
\text { - Provide mechanisms for research into the } \\
\text { refinement of administrative boundary data. }\end{array}$ \\
\hline
\end{tabular}

\subsection{CONCLUSION}

Administrative boundaries are a product of both the era and the constraints of the individual agencies for which they were developed. This chapter demonstrates the significance of administrative boundaries within the SDI framework. Additionally, the chapter highlights one of the most prevalent problems currently limiting the use of data within a number of GIS applications: the spatial-hierarchy problem. In response to this problem, a number of technical developments have been made in 
the areas of surface modelling, interpolation, derived boundaries, and the reaggregation of point and polygon data. These developments have contributed to a better understanding of the problem and nature of incompatible boundaries however, as the spatial industry expands, more accurate solutions are required. The research summarised in this chapter has demonstrated that the reorganization of boundaries into a coordinated spatial hierarchy is possible. However, as stated previously in this chapter developing a technical solution alone cannot ensure the development of a hierarchy of administrative boundaries until an organised SDI infrastructure is in place (see Chapter 2).

As SDI develops as a mechanism facilitating the transfer and access of spatial data to a wide array of data users the structuring of administrative boundaries in a coordinated manner will become increasingly important. This chapter has focussed specifically on the role and developments necessary to incorporate the unique properties of administrative boundaries within the SDI.

\subsection{REFERENCES}

ABS., 1998, Australian Standard Geographical Classification (ASGC), The Australian Bureau of Statistics, Canberra, 12160.0.

Bracken, I., 1994, A Surface Model Approach to the Representation of PopulationRelated Social Indicators, In Spatial analysis and GIS, Edited by Fotheringham, S. and Rogerson, P., (Bristol: Taylor \& Francis), pp. 247-260.

Car, A., 1997, Hierarchical Spatial Reasoning: Theoretical Consideration and its Application to Modeling Wayfinding, PhD thesis, Department of Geoinformation, Technical University Vienna.

Chan, T.O., Feeney, M., Rajabifard, A. and Williamson, I.P., 2001, The Dynamic Nature of Spatial Data Infrastructures: A Method of Descriptive Classification. Geomatica 55(1): 65-72.

DASC, 1999, Kansas Geospatial Data Standards: Jurisdictional and Administrative Boundaries, State of Kansas Data Access and Support Center (DASC), Kansas.

Dale, P. and McLaughlin, J., 1988, Land Information Management, (New York: Oxford University Press).

Duke-Williams, O. and Rees, 1998, Can census offices publish statistical for more than one small area geography? An analysis of the differencing problem in statistical disclosure, International Journal Geographical Information Science, vol. 12, no. 6, pp. 579-605.

Eagleson, S., Escobar, F. and Williamson, I. P., 2002a, Hierarchical spatial reasoning theory and GIS technology applied to the automated delineation of administrative boundaries. Computers, Environment and Urban Systems, no. 26, pp. 185-200.

Eagleson, S., Escobar, F. and Williamson, I. P., 2002b, Automating the Administrative Boundary Design Process using Hierarchical Spatial Reasoning Theory and GIS, International Journal of Geographical Information Science, (in press).

Escobar, F., Green, J., Waters, E. and Williamson, I., 2001, Geographic Information Systems for the Public Health: A proposal for a research agenda, In 
Geography and Medicine. Geomed'99, Edited by Flahault, A., Toubiana, L. and Valleron, A., (Paris: Elsevier), pp. 139-148.

Feeney, M.E.F, Williamson, I.P. and Bishop, I.D., 2002, The Decision Support Role of Institutional Mechanisms in Spatial Data Infrastructure. Cartography Journal 3, No 2, pp 22-37.

Flowerdew, R. and Green, M., 1994, Area interpolation and types of data, in Spatial Analysis and GIS, Edited by Fotheringham, S. and Rogerson, P., (London: Taylor and Francis), pp. 121- 145.

Fotheringham, A. and Wong, D., 1991, The Modifiable Area Unit Problem, Environment and Planning $A, 23$, pp. 1025-1044.

Geoscience Australia, 2001, Administrative boundaries, Online.

$<$ http://www.auslig.gov.au/products/digidat/admin.htm> (Accessed March 2002).

Goodchild, M., Anselin and Deichmann, U., 1993, A framework for the areal interpolation of socioeconomic data, Environment and Planning $A$, vol. 25, pp. 383-397.

Hugo, G., 1997, Putting People back into the Planning Process: The changing role of Geographical Information Systems, Online.

$<$ http://www.gisca.adelaide.edu.au/gisca/hugo_paper.html $>$ (Accessed May 2002).

Huxhold, W., 1991, An introduction to urban Geographic Information Systems, (Oxford: Oxford University Press).

Jones, S. D., Eagleson, S., Escobar, F. and Hunter, G. J., 2003, Lost in the mail: The inherent errors of mapping Australia Post postcodes to ABS derived postal areas, Australian Geographical Studies (In press).

Martin, D. and Bracken, I., 1991, Techniques for modelling population-related raster databases, Environment and Planing A, 23, pp. 1069-1075.

Martin, D., 1998, Optimizing census geography: the separation of collection and output geographies, International Journal of Geographical Information Science, vol. 12 , no. 7, pp. 673-685.

Marquardt, W. R. and Crumley, C. L., 1987, Theoretical issues in the analysis of spatial planning, In Regional dynamics: Burgyndian landscapes in historical perspective, Edited by Crumley, C. L. and Marquardt, W. H., (San Diego: Academic Press), pp. 1-17.

Mobbs, J., 1998, Australia comes to its census, Proceedings of FIG 7, Melbourne Australia, p. 14.

Morphet, C., 1993, The mapping of small area census data - a consideration of the effects of enumeration district boundaries, Environment and Planning A, vol. 25, 9, pp. 1267-1277.

Nairn, A. and Holland, P., 2001, The NGDI of Australia: Achievements and challenges from federal perspectives, Online.

$<\mathrm{http} / /$ www.gisdevelopment.net/application/gii/global/giigp0003.htm> (Accessed October 2001).

Openshaw, S., 1998, Toward a more computationally minded scientific human geography, Environment and Planning A, vol. 30, pp. 317-332.

Openshaw, S., 1977, An optimal zoning approach to the study of spatially aggregated data, In Spatial Representation and Spatial Interaction, Edited by Masser, I. \& Brown, P., (Leiden: Martinus Nijhoff), pp. 96-113. 
Openshaw, S. and Alvanides, S., 1999, Applying geocomputation to the analysis of spatial distributions. In Geographic Information Systems: Principles and Technical Issue, Edited by Longley, P., Goodchild, M., Maguire, D. and Rhind, D., (New York: John Wiley and Sons).

Openshaw, S., Alvanides, S. and Whalley, S., 1998, Some further experiments with designing output areas for the 2001 UK census, Online.

$<$ http://www.geog.soton.ac.uk/research/oa2001/resources.htm>

(Accessed November 2000).

Openshaw, S. and Rao, L., 1995, Algorithms for reengineering 1991 Census geography, Environment and Planning A., no. 27, pp. 425-446.

Rajabifard, A., Escobar, F. and Williamson, I. P., 2000, Hierarchical spatial reasoning applied to Spatial Data Infrastructure, Cartography, vol. 29, No. 2, pp. 41-50.

Rajabifard, A. and Williamson, I. P., 2001, Spatial Data Infrastructures: Concept, SDI hierarchy and future directions, Geomatics'80 Conference, Tehran, Iran. Online.

$<$ http://www.geom.unimelb.edu.au/research/publications/IPW/4_01Raj_Iran.pdf $>$ (Accessed October 2002).

Robinson, J.M. and Zubrow, E., 1997, Restoring continuity: Exploration of techniques for reconstructing the spatial distribution underlying polygonized data, International Journal of Geographical Information Science, vol. 11, no. 7, pp. 633-648.

Timpf, S. and Frank, A. U., 1997, Using hierarchical spatial data structures for hierarchical spatial reasoning. In Spatial Information Theory - A Theoretical Basis for GIS (International Conference COSIT'97), Edited by Hirtle, Stephen C. and Frank, Andrew U. Lecture Notes in Computer Science 1329, (BerlinHeidelberg: Springer-Verlag).

Trinidad, G. and Crawford, J., 1996, A tool for transferring attributes across thematic maps, $A M / F M$, pp. 127-137.

UCGIS, 2000, Spatial analysis in a GIS environment, Online.

$<$ http://www.ucgis.org/research_white/anal.html> (Accessed October 2001).

Volta, G., and Egenhofer, M., 1993, Interaction with GIS Attribute Data Based on Categorical Coverages. In European Conference on Spatial Information Theory, Edited by A. Frank and I. Campari, (Italy: Marciana Marina). 